\title{
A Case of Typical Chest Pain: Takotsubo Cardiomyopathy Following Rhabdomyolysis
}

Ramyashree Tummala1*, Sravani Kamatam¹, Keyvan Ravakhah¹, Anjan Gupta1, Rajesh Sonani², and Samir Patel ${ }^{3}$

${ }^{1}$ St. Vincent Charity Medical Center, An Affiliate of Case Western Reserve University, Cleveland, OH, USA

${ }^{2}$ Brandon Regional Hospital, Brandon, FL, USA

${ }^{3}$ Sparks Health Systems, An Affiliate of University of Arkansas Medical Sciences West, Fort Smith, AR, USA

\begin{abstract}
Takotsubo cardiomyopathy (TCM) is a reversible disorder characterized by left ventricular wall apical ballooning precipitated by stressful event. Clinical presentation of this disorder mimics acute coronary syndrome (ACS). We are presenting a case of TCM, which is unique as rhabdomyolysis being the triggering factor. Although, our patient presented with features of NSTEMI on EKG and elevated troponins, diagnosis of TCM was made by echocardiography which showed left ventricular apical wall hypokinesis with Left ventriculogram showing the apical ballooning. The unique feature of the case was the triggering factor being rhabdomyolysis.
\end{abstract}

Keywords: Cardiomyopathy; Chest pain; Coronary angiography; Echocardiography

\section{Introduction}

Takotsubo cardiomyopathy (TCM) is a transient heart syndrome mimics acute coronary syndrome (ACS), exhibiting chest pain, ischemic electrocardiographic changes, elevated cardiac enzymes and left ventricular (LV) apical wall motion abnormalities with non-obstructive coronary angiogram [1]. The name "Takotsubo" is a Japanese term for octopus trap, was first used by Satoh et al. and Dote et al. to describe the LV apical ballooning which resembles pot with a narrow neck and round base [2]. Studies have shown that patients with TCM usually have good prognosis and less recurrence rate [3].

\section{Case Presentation}

An 83-year-old male was brought in by EMS with history of unwitnessed fall and was found on floor. His past medical history includes hypertension, and he was on carvedilol and lisinopril with no other medications. On admission, his vitals were temperature 36.4 , pulse rate 66, respiratory rate 18 and blood pressure 138/75 $\mathrm{mm}$ of Hg. On physical examination, he had no neurological deficits and had basal crackles on lung examination bilaterally and muscle tenderness bilaterally in lower limbs. Rest of the physical examination was unremarkable. Later he complained of left sided chest pain. Chest $\mathrm{X}$ ray on admission was suggestive of pulmonary vascular congestion. EKG revealed $\mathrm{T}$ wave inversions in V1-V6. Troponin on admission was 4.9 $\mathrm{ng} / \mathrm{ml}$ and the repeat troponin after 6 hours was $5.8 \mathrm{ng} / \mathrm{ml}$ (Normal $0.01 \mathrm{ng} / \mathrm{ml}$ to $0.045 \mathrm{ng} / \mathrm{ml}$ ), Brain Natriuretic Peptide was $2509 \mathrm{pg} / \mathrm{ml}$ (Normal $<100 \mathrm{pg} / \mathrm{ml}$ ), Creatinine Kinase was 13,575 U/L (Normal 39 $\mathrm{U} / \mathrm{L}$ to $308 \mathrm{U} / \mathrm{L})$ and Creatinine Kinase $\mathrm{MB}$ was $53 \mathrm{ng} / \mathrm{ml}(0.5 \mathrm{ng} / \mathrm{ml}$ to $3.6 \mathrm{ng} / \mathrm{ml}$ ), creatinine $0.9 \mathrm{mg} / \mathrm{dl}$ (Normal $0.7 \mathrm{mg} / \mathrm{dl}$ to $1.3 \mathrm{mg} / \mathrm{dl}$ ) and Blood Urea Nitrogen $20 \mathrm{mg} / \mathrm{dl}$ (Normal $7 \mathrm{mg} / \mathrm{dl}$ to $18 \mathrm{mg} / \mathrm{dl}$ ). After admission, diagnosis of rhabdomyolysis was made and administration of intravenous fluids improved his CK levels. Transthoracic echo was done which showed moderately dilated left ventricular chamber size with multiple regional wall abnormalities. The estimated ejection fraction was $30 \%$ to $35 \%$. The mid anteroseptal, mid anterior, apical septal, apical anterior, apical, lateral, and apical inferior wall segments were akinetic as shown in Figure 1. He was treated as NSTEMI with heparin, aspirin, plavix, statin and cardiac catheterization was planned on next day. Cardiac catheterization showed no coronary artery disease as shown in Figures 2 and 3. Left ventriculography revealed globally

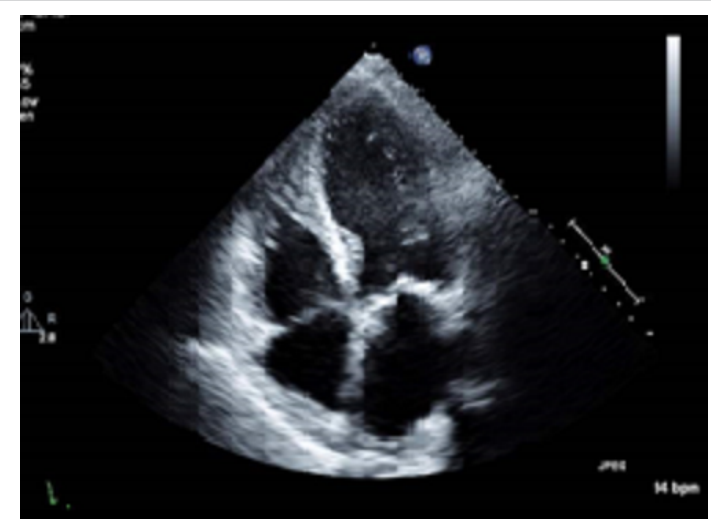

Figure 1: Transthoracic echocardiography: Apical ballooning: Showing akinesis of the LV apex.

moderate to severely decreased left ventricular systolic function with ejection fraction of $35 \%$ with evidence of anterior anteroapical and inferoapical hypokinesis suggestive of Takotsubo cardiomyopathy as shown in Figure 4. He was well hydrated, started on beta blocker and on the day of discharge, his EKG showed resolved T wave inversions. He was discharged in a stable condition with a final diagnosis of Takotsubo cardiomyopathy with rhabdomyolysis as a triggering factor, with follow up echocardiogram.

\section{Case Discussion}

Left Ventricular Apical Ballooning syndrome also known as TCM is reversible condition usually precipitated by stressful event whose clinical presentation is difficult to differentiate from acute coronary

*Corresponding authors: Ramyashree Tummala, Department of Internal Medicine St. Vincent Charity Medical Center, An Affiliate of Case Western Reserve University, Cleveland, 2351 E 22nd street, OH 44114, USA, E-mail: ramyashree19@gmail.com

Received April 19, 2017; Accepted May 04, 2017; Published May 08, 2017

Citation: Tummala R, Kamatam S, Ravakhah K, Gupta A, Sonani R, et al (2017) A Case of Typical Chest Pain: Takotsubo Cardiomyopathy Following Rhabdomyolysis. J Cardiovasc Dis Diagn 5: 272. doi: 10.4172/2329-9517.1000272

Copyright: (c) 2017 Tummala R, et al. This is an open-access article distributed under the terms of the Creative Commons Attribution License, which permits unrestricted use, distribution, and reproduction in any medium, provided the original author and source are credited. 


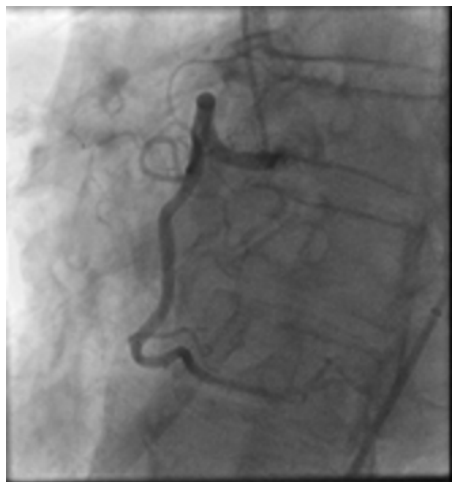

Figure 2: Coronary angiography: Showing normal right coronary artery.

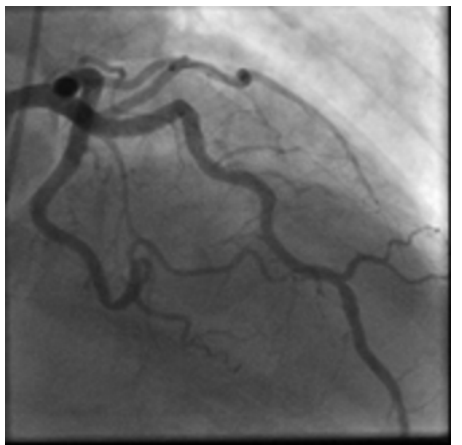

Figure 3: Coronary angiography: Showing normal left coronary arteries.

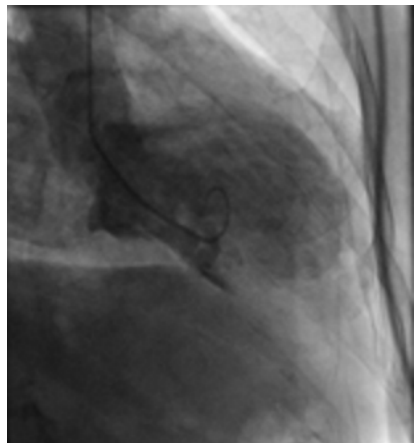

Figure 4: Left ventriculogram, demonstra ting the apical ballooning typical in Takotsubo cardiomyopathy.

syndrome. The incidence of TCM among patients presenting as ACS is noted to be $1 \%$ to $2 \%$ [4]. The pathophysiology is unknown, but the theory of catecholamine release during stressful situations and its effect on myocardium causing microvascular dysfunction is widely accepted [5]. Sudden exposure to emotional or physical stress is known to precipitate the event. The symptoms of chest pain with elevated cardiac enzymes and EKG changes highly suggest acute myocardial infarction. The diagnostic algorithm for transient left ventricular apical ballooning was proposed by Mayo Clinic which is useful tool for recognizing the patients with this condition [6]. Our patient had typical presentation of acute chest pain, elevated troponin and EKG changes mimicking ACS which was ruled out by coronary angiography. The diagnosis of TCM was confirmed by the echocardiography which showed left ventricular apical wall hypokinesis with Left ventriculogram showing the apical ballooning. The unique feature of the case was the triggering factor being rhabdomyolysis. On reviewing the literature only one case report has been published so far by Mbogori et al. which describes case of TCM following fall due to rhabdomyolysis [7]. Another case series published by Sharma et al. highlights the incidence of TCM cases in tertiary center and underutilization of left ventriculography might be a reason for missing TCM cases [8]. Iyer et al. have published a case report which describes emotional stress as trigger factor for acute chest pain presentation in a female patient who was later diagnosed with stress cardiomyopathy [9]. The international Takotsubo registry mentions TCM to be benign and risk of major adverse cardiac and cerebrovascular outcome was $9.9 \%$ and death risk is $5.6 \%$ per patientyear $[10,11]$. The most commonly proposed treatment is use of beta blockers and angiotensin-converting enzyme inhibitors [12].

\section{Conclusion}

Our case will be an important addition to the literature as it describes rhabdomyolysis as one of the triggering factors of Takotsubo cardiomyopathy, a rare presentation. Echocardiography and left ventriculography are generally used for diagnosis during the typical presentation of chest pain with elevated troponins. We also want to highlight the importance of having TCM as a differential in patients with acute chest pain following physical stress like rhabdomyolysis.

\section{Case Highlights and Importance}

1. Takotsubo Cardiomyopathy (TCM) usually mimics Acute Coronary Syndrome.

2. Diagnosis of TCM is by Left ventriculogram which shows apical ballooning.

3. TCM can be precipitated by physical stress like rhabdomyolysis. TCM.

4. Beta blockers and ACE inhibitors are shown to be treatment for

5. Studies have shown that TCM has good prognosis and less recurrence rate.

\section{Conflict of Interest: None}

\section{Acknowledgement: None}

\section{References}

1. Parodi G, Del Pace S, Carrabba N, Salvadori C, Memisha G, et al. (2007) Incidence, clinical findings, and outcome of women with left ventricular apical ballooning syndrome. Am J Cardiol 99: 182-185.

2. Tsuchihashi K, Ueshima K, Uchida T, Oh-mura N, Kimura K, et al. (2001) Transient left ventricular apical ballooning without coronary artery stenosis: $A$ novel heart syndrome mimicking acute myocardial infarction. J Am Coll Cardiol 38: 11-18.

3. Elesber AA, Prasad A, Lennon RJ, Wright RS, Lerman A, et al. (2007) Fouryear recurrence rate and prognosis of the apical ballooning syndrome. $\mathrm{J} A m$ Coll Cardiol 50: 448-452.

4. Prasad A, Lerman A, Rihal CS (2008) Apical ballooning syndrome (Tako-Tsubo or stress cardiomyopathy): A mimic of acute myocardial infarction. Am Heart $J$ 155: 408-417.

5. Komamura K, Fukui M, Iwasaku T, Hirotani S, Masuyama T (2014) Takotsubo cardiomyopathy: Pathophysiology, diagnosis and treatment. World $\mathrm{J}$ Cardiol 6: 602-609.

6. Kawai S, Kitabatake A, Tomoike H; Takotsubo Cardiomyopathy Study Group (2007) Guidelines for diagnosis of takotsubo (ampulla) cardiomyopathy. Circ J 71: 990-992.

7. Mbogori J, Chawdhary K, Vacek JL (2010) A man with a worried heart: Transient left ventricular Apical Ballooning and Rhabdomyolysis. Am J Med 123: e11-e12. 
Citation: Tummala R, Kamatam S, Ravakhah K, Gupta A, Sonani R, et al. (2017) A Case of Typical Chest Pain: Takotsubo Cardiomyopathy Following Rhabdomyolysis. J Cardiovasc Dis Diagn 5: 272. doi: 10.4172/2329-9517.1000272

Page 3 of 3

8. Sharma V, Srinivasan M, Sheehan DM, Ionescu A(2013) Stress cardiomyopathy: Case series and the review of literature. J Emerg Med 45: e95-e98.

9. Iyer S, Shivtarkar S, UdyavarA(2016) Takotsubo cardiomyopathy masquerading as acute coronary syndrome. J Assoc Physicians India 64: 87.

10. Ghadri JR, Cammann VL, Templin C (2016) The international Takotsubo registry: Rationale, design, objectives, and first results. Heart Fail Clin 12: 597-603.
11. Templin C, Ghadri JR, Diekmann J, Napp LC, Bataiosu DR, et al. (2015) Clinical features and outcomes of takotsubo (stress) cardiomyopathy. N Eng J Med 373: 929-938.

12. Bastante T, Rivero F, Cuesta J, Benedicto A, Restrepo J, et al. (2014) Nonatherosclerotic causes of acute coronary syndrome: Recognition and management. Curr Cardiol Rep 16: 543 